Short Note

\title{
Chitooligosaccharide-2,5-anhydro-D-mannonic Acid
}

\section{Emil Salim, Daniela Ailincai and Stéphane Trombotto *}

Ingénierie des Matériaux Polymères (IMP, UMR CNRS 5223), Université Claude Bernard Lyon 1, Université de Lyon, Villeurbanne F-69622, France

* Author to whom correspondence should be addressed; E-Mail: stephane.trombotto@univ-lyon1.fr; Tel.: +33-4-7243-1210; Fax: +33-4-7243-1249.

Received: 26 June 2014 / Accepted: 14 August 2014 / Published: 19 August 2014

\begin{abstract}
Chitooligosaccharide with one 2,5-anhydro-D-mannofuranose unit at the reducing end (COSamf) was prepared by nitrous deamination of fully $N$-deacetylated chitosan. The oxidation of the amf-unit by chlorite sodium was achieved in high yield. The chemical structure of the targeted chitooligosaccharide-2,5-anhydro-D-mannonic acid with a degree of polymerization $\sim 10$ was fully characterized by NMR spectroscopy, MALDI-TOF mass spectrometry and size-exclusion chromatography. The success of this synthesis opens the way to a new generation of end-functionalized COS building blocks.
\end{abstract}

Keywords: chitosan; chitooligosaccharide-2,5-anhydro-D-mannofuranose; 2,5-anhydro-Dmannonic acid; nitrous deamination; oxidation

Chitosan is a linear polysaccharide of D-glucosamine $(\mathrm{GlcN})$ and N-acetyl-D-glucosamine (GlcNAc) units linked by $\beta-(1 \rightarrow 4)$ glycosidic bonds. Chitosan is produced industrially by alkaline $\mathrm{N}$-deacetylation of chitin, the second most abundant naturally occurring polymer, mainly present in the exoskeleton of arthropods and in the endoskeleton of cephalopods [1,2]. Chitosan and chitin oligomers, also named chitooligosaccharides (COS), have recently received considerable attention as functional biomolecules with a wide range of applications in food, agriculture, medicine, pharmaceutics and cosmetics. COS take advantage of their various remarkable physico-chemical and biological properties, including water-solubility, biocompatibility, antibacterial, antifungal and antitumoral activities $[3,4,5,6]$.

Among various chemical methods described in the literature for the preparation of COS by depolymerisation of chitin or chitosan, the nitrous acid $\left(\mathrm{HNO}_{2}\right)$ deamination methodology presents several advantages: $(i)$ the reaction is selective and rapid; (ii) the reaction can be carry out in 
homogeneous aqueous solutions and mild reaction conditions of temperature and $\mathrm{pH}$; (iii) the extent of depolymerisation can be controlled through the stoichiometry of reaction $[7,8,9]$. The mechanism has been found to be specific in the sense that $\mathrm{HNO}_{2}$ attacks the amino group of GlcN-units, with a subsequent cleavage of the following glycosidic linkage and a formation of 2,5-anhydro-Dmannofuranose (amf-unit) at the position corresponding to the reducing end. Because the amf-residue in COS is rather unstable in mild acidic conditions, due to its decomposition to hydroxylmethylfurfural (HMF), the standard procedure has been its reduction to 2,5-anhydro-D-mannitol by $\mathrm{NaBH}_{4}[10,11]$.

In order to develop a new easy access of stable COS from nitrous deamination of chitosan, the oxidation of the aldehyde group of amf-units in COS has been studied. We describe here the synthesis and the characterisation of chitooligosaccharide-2,5-anhydro-D-mannonic acid with a low degree of polymerization (DP) $\sim 10$ by reaction of COSamf with sodium chlorite. Furthermore, the acid group of 2,5-anhydro-D-mannonic acid could be available for reactions that could make the obtained COS an interesting precursor in organic synthesis.

\section{Results and Discussion}

Chitooligosaccharide-2,5-anhydro-D-mannonic acid with an average GlcN-units number into chains around 10, was efficiently synthesized from chitosan in a one pot two-step procedure involving the aldehyde group oxidation of the intermediate chitooligosaccharide-2,5-anhydro-D-mannofuranose (COSamf 1) with sodium chlorite as illustrated in Scheme 1.

Scheme 1. Synthesis of chitooligosaccharide-2,5-anhydro-D-mannonic acid (2) from chitosan.

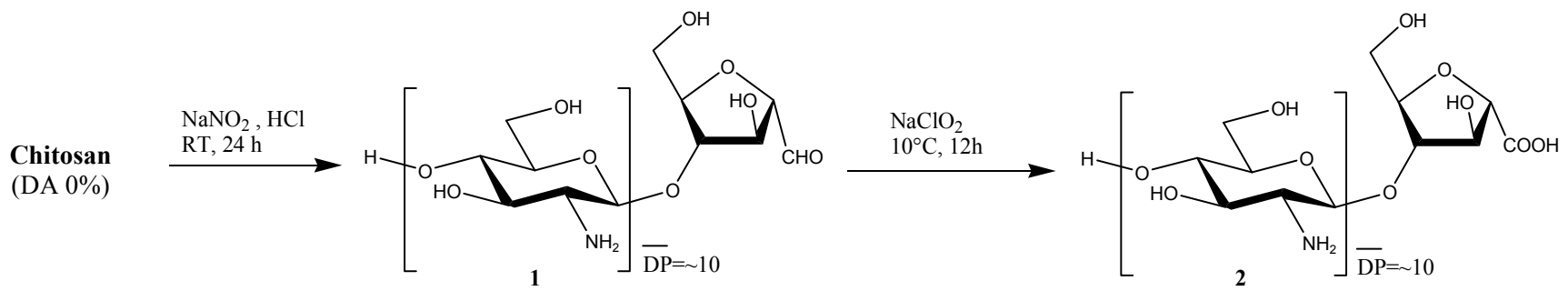

Thus, COSamf 1 was produced by nitrous acid deamination of a fully $N$-deacetylated chitosan as described in a previous study [12]. Briefly, the depolymerization of chitosan (DA $0 \%, \overline{\mathrm{Mw}}=270 \mathrm{~kg} / \mathrm{mol}$; $\overline{\mathrm{Mn}}=115 \mathrm{~kg} / \mathrm{mol}, \mathrm{Ð}=2.3)$ was carried out using sodium nitrite $\left(\mathrm{GlcN} / \mathrm{NaNO}_{2}\right.$ molar ratio $\left.=4\right)$ in aqueous acid solution at room temperature. After $24 \mathrm{~h}$ of reaction, COSamf 1 could be isolated and purified in $80 \%$ mass yield by both ultrafiltration and precipitation in ethanol. The chemical structure of COSamf 1 was fully confirmed by ${ }^{1} \mathrm{H}$ and ${ }^{13} \mathrm{C}-\mathrm{NMR}$ spectroscopies, MALDI-TOF mass spectrometry and size-exclusion chromatography (see Supporting Information). Therefore it has been shown COSamf 1 is composed of a mixture of GlcN-unit oligomers, with an average DP around 10.

In a second step, the selective oxidation of the amf-unit aldehyde group by sodium chlorite has been directly carried out after the nitrous deamination step at $10{ }^{\circ} \mathrm{C}$ for $12 \mathrm{~h}$, leading to the targeted chitooligosaccharide-2,5-anhydro-D-mannonic acid $\mathbf{2}$ in a good mass yield (70\%) from chitosan, after purification by ultrafiltration and precipitation in ethanol. The chemical structure of the compound 2 was fully characterized by ${ }^{1} \mathrm{H}$ and ${ }^{13} \mathrm{C}-\mathrm{NMR}$ spectroscopies thanks to two-dimensional NMR analyses, pointing out the loss of the aldehyde group at $5.1 \mathrm{ppm}$ in the ${ }^{1} \mathrm{H}-\mathrm{NMR}$ spectrum and the formation of 
the carboxylic group at $175.0 \mathrm{ppm}$ in the ${ }^{13} \mathrm{C}-\mathrm{NMR}$ spectrum [13]. As confirmed by MALDI-TOF mass spectrometry, chitooligosaccharide-2,5-anhydro-D-mannonic acid $\mathbf{2}$ is composed of a mixture of GlcN-unit oligomers (see Supporting Information). The average number of GlcN units into chains was determined by both ${ }^{1} \mathrm{H}-\mathrm{NMR}$ and SEC and was found to be equal to around 10, as for COSamf 1. Additionally, it has been shown this oxidation procedure can be carried out on COSamf with higher average GlcN-units number into chains, i.e. DP $\sim 20$ and $\sim 30$, leading to corresponding chitooligosaccharide-2,5-anhydro-D-mannonic acids in high mass yields from chitosan, respectively $80 \%$ and $90 \%$.

As expected, chitooligosaccharide-2,5-anhydro-D-mannonic acid 2 has shown a good stability in both aqueous solution and powder form at low to room temperatures over several months. Thus, no decomposition into HMF residues was observed in ${ }^{1} \mathrm{H}-\mathrm{NMR}$ analyses, contrarily to what could be shown for COSamf $\mathbf{1}$ in same storage conditions.

\section{Experimental}

Chitooligosaccharide-2,5-anhydro-D-mannonic acid 2: A fully $N$-deacetylated chitosan $(2.1 \mathrm{~g}, 13 \mathrm{mmol}$ GlcN unit) was solubilized in $100 \mathrm{~mL}$ of water by addition of $1.15 \mathrm{~mL} \mathrm{HCl}(37 \% \mathrm{w} / \mathrm{w})$. Then, a freshly prepared $5 \mathrm{~mL}$ aqueous solution of $\mathrm{NaNO}_{2}(0.66 \mathrm{M})$ was added and the reaction was allowed to proceed for $24 \mathrm{~h}$ at room temperature. For isolation and characterisation of COSamf $\mathbf{1}$, the solution was neutralised $(\mathrm{pH} \mathrm{7-8)}$ by $1 \mathrm{M}$ sodium hydroxide, then ultra-filtered (cellulose ester membrane, MWCO 500, Spectrum Labs). COSamf 1 was obtained as a white powder after precipitation in ethanol and drying under vacuum ( $1.7 \mathrm{~g}, 80 \%$ mass yield). For the oxidation step, a $30 \mathrm{~mL}$ aqueous solution of sodium chlorite $(0.45 \mathrm{M})$ was added at $10{ }^{\circ} \mathrm{C}$ to the COSamf 1 solution obtained after the nitrous deamination step, and the reaction was stirred for $12 \mathrm{~h}$ at RT. The solution was neutralised (pH 7-8) by sodium hydroxide, then ultra-filtered (cellulose ester membrane, MWCO $500 \mathrm{~g} / \mathrm{mol}$, Spectrum Labs). The product was precipitated in ethanol and drying under vacuum leading to compound $\mathbf{2}$ as white powder (1.5 g, 70\% total mass yield). ${ }^{1} \mathrm{H}-\mathrm{NMR}\left(300 \mathrm{MHz}, \mathrm{D}_{2} \mathrm{O}, 298{ }^{\circ} \mathrm{K}\right): \delta(\mathrm{ppm}) 4.70(\mathrm{~m}, \mathrm{H}-3 \mathrm{amf})$, 4.58 (d, $J=3.0 \mathrm{~Hz}, \mathrm{H}-2 \mathrm{amf}), 4.30$ (m, H-5 amf), 4.22 (m, H-4 amf), 4.00-3.40 (m, H-3 to H-6 GlcN, H-6 amf), 3.18 (m, H-2 GlcN). ${ }^{13} \mathrm{C}-\mathrm{NMR}\left(125 \mathrm{MHz}, \mathrm{D}_{2} \mathrm{O}, 298{ }^{\circ} \mathrm{K}\right): \delta(\mathrm{ppm}) 175.0(\mathrm{COOH}), 99.1$ (C-1' GlcN), 98.2 (C-1 GlcN), 86.0 (C-4 amf), 84.9 (C-5 amf), 82.8 (C-2 amf), 79.3 (C-3 amf), 77.1 (C-5' GlcN), 77.0 (C-4 GlcN), $75.5(\mathrm{C}-5 \mathrm{GlcN}), 72.4\left(\mathrm{C}-3{ }^{\prime} \mathrm{GlcN}\right), 70.7$ (C-3 GlcN), 70.3 (C-4' GlcN), 61.8 (C-6 amf), $61.0\left(\mathrm{C}-6{ }^{\prime} \mathrm{GlcN}\right), 60.7$ (C-6 GlcN), $56.6(\mathrm{C}-2 \mathrm{GlcN}), 56.3\left(\mathrm{C}-2^{\prime} \mathrm{GlcN}\right)$. Note that $C^{\prime}$ represents carbon atoms of the GlcN unit linked to the amf unit. MALDI-TOF MS: presence of a major peak at $\mathrm{m} / z \quad 990.5$ attributed to $\mathrm{HO}-(\mathrm{GlcN})_{5}-\mathrm{C}_{6} \mathrm{H}_{9} \mathrm{O}_{4} \quad(\mathrm{~m} / z$ monoisotopic calcd for $\left[\mathrm{C}_{36} \mathrm{H}_{65} \mathrm{O}_{25} \mathrm{~N}_{5} \mathrm{Na}\right]^{+}=990.4$ mass units $(\Delta=0.01 \%)$ ). HRMS (ESI): calcd for $\mathrm{C}_{36} \mathrm{H}_{65} \mathrm{O}_{25} \mathrm{~N}_{5} \mathrm{Na}: \mathrm{m} / z$ 990.3866; found $990.3850[\mathrm{M}+\mathrm{Na}]^{+}($difference $=1.6 \mathrm{ppm})$.

\section{Acknowledgments}

The authors thank Catherine Ladavière (IMP, CNRS), Agnès Crepet (IMP, CNRS) and Bernard Fenet (CCRMN, Université Lyon 1) for their helpful assistance and discussions in MALDI-TOF mass spectrometry, size-exclusion chromatography and NMR spectroscopy analyses, respectively. Financial support from the University Lyon 1 is greatly acknowledged. 


\section{Author Contributions}

All the authors equally contributed to the research. ES and DA did the experiments. ST performed the spectroscopy data and wrote the paper.

\section{Conflicts of Interest}

The authors declare no conflict of interest.

\section{References and Notes}

1. Dash, M.; Chiellini, F.; Ottenbriteb, R.M.; Chiellini, E. Chitosan: A versatile semi-synthetic polymer in biomedical applications. Prog. Polym. Sci. 2011, 36, 981-1014.

2. Yeul, V.S.; Rayalu, S.S. Unprecedented Chitin and Chitosan: A Chemical Overview. J. Polym. Environ. 2013, 21, 606-614.

3. Aam, B.B.; Heggset, E.B.; Norberg, A.L.; Sørlie, M.; Vårum, K.M.; Eijsink, V.G.H. Production of chitooligosaccharides and their potential applications in medicine. Mar. Drugs 2010, 8, 1482-1517.

4. Xia, W.; Liu, P.; Zhang, J.; Chen, J. Biological activities of chitosan and chitooligosaccharides. Food Hydrocolloids 2011, 25, 170-179.

5. Lodhi, G.; Kim, Y.-S.; Hwang, J.-W.; Kim, S.-K.; Jeon, Y.-J.; Je, J.-Y.; Ahn, C.-B.; Moon, S.-H.; Jeon, B.-T.; Park, P.-J. Chitooligosaccharide and Its Derivatives: Preparation and Biological Applications. BioMed Res. Int. 2014, 2014, doi:10.1155/2014/654913.

6. Trombotto, S.; Ladavière, C.; Delolme, F.; Domard, A. Chemical preparation and structural characterization of a homogeneous series of chitin/chitosan oligomers. Biomacromolecules 2008, 9, 1731-1738.

7. Tommeraas, K.; Varum, K.M.; Christensen, B.E.; Smidsrod, O. Preparation and characterization of oligosaccharides produced by nitrous acid depolymerization of chitosans. Carbohydr. Res. 2001, 333, 137-144.

8. Hussain, I.; Singh, T.; Chittenden, C. Preparation of chitosan oligomers and characterization: their antifungal activities and decay resistance. Holzforschung 2012, 66, 119-125.

9. Mourya, V.K.; Inamdar, N.N.; Choudhari, Y.M. Chitooligosaccharides: Synthesis, characterization and applications. Polym. Sci. Ser. A Polym. Phys. 2011, 53, 583-612.

10. Sashiwa, H.; Saimoto, H.; Shigemas, Y.; Tokura, S. Chitooligosaccharides: Synthesis, characterizations and applications. Carbohydr. Res. 1993, 242, 167-172.

11. Lin, C.-W.; Lin, J.-C. Characterization and blood coagulation evaluation of the water-soluble chitooligosaccharides prepared by a facile fractionation method. Biomacromolecules 2003, 4, 1691-1697.

12. Salim, E.; Galais, A.; Trombotto, S. 4-(Hexyloxy)aniline-linked chitooligosaccharide-2,5anhydro-D-mannofuranose. Molbank 2014, 2014, M815.

13. Note that in the ${ }^{1} \mathrm{H}-\mathrm{NMR}$ analysis conditions used here, the aldehyde group of the amf-units does not exist in its free $(-\mathrm{CHO})$ form but exclusively in its hydrated $\left(-\mathrm{CH}(\mathrm{OH})_{2}\right)$ form.

(C) 2014 by the authors; licensee MDPI, Basel, Switzerland. This article is an open access article distributed under the terms and conditions of the Creative Commons Attribution license (http://creativecommons.org/licenses/by/3.0/). 